\title{
The Impact of Salesforce Motivation on Organizational Performance in Pharmaceutical Industry of Karachi, Pakistan, 2019
}

\author{
Bakhtiyar Ali (Author) \\ MBA Marketing \\ Karachi University Business School, University of Karachi \\ PO Box 75270, Main University Rd, University of Karachi, Karachi, Karachi City \\ Tel: 923-351-335-253Ｅ-mail: bakhtiyar45@gmail.com
}

Muhammad Abu Bakr Ali (Corresponding author)

MBA Marketing

Karachi University Business School, University of Karachi

PO Box 75270, Main University Rd, University of Karachi, Karachi, Karachi City

Tel: 923-362-509-210 E-mail: abubakrali02@gmail.com

Dr. Shameel Ahmed Zubairi (Research Supervisor)

Assistant Professor

Karachi University Business School, University of Karachi

Tel: 923-333-626-726_E-mail: sazubairi@uok.edu.pk

Received: May 5, 2020

Accepted: May 22, 2020

Published: June 15, 2020

doi:10.5296/ijim.v5i1.17196 URL: https://doi.org/10.5296/ijim.v5i1.17196

\begin{abstract}
The pharmaceutical industry in Pakistan is a very demanding market that is always subject to competitive pressures. This research objects to define the interaction (Intrinsic, Extrinsic) of motivational factors for the salesforce teams in pharmaceuticals with respect to company performance. It will test the relevance of modern motivation theories in their attempt to
\end{abstract}




\section{Macrothink}

explain the importance of the determinants of motivation in the context of performance by the sales force in Karachi, Pakistan For the execution of the current research and catering to the research questions in an effective manner, researcher opts for quantitative research design. In this research, the study has focused on selecting the population who belong only from the industry of pharmaceutical companies operating in Karachi. The sample size selected is based on 200 participants belonging from only pharmaceutical-based organizations. The research is based on using the primary method that involves collecting data or information directly from the real world. The design of questionnaire initiates from the demographic info to motivational factors like intrinsic variables, extrinsic variables along with the mediating variables and ending with company factor of performance questions. Data is analyzed by means of statistical tests and quantitative strategies. Primary data collected through the survey process is analyzed by Multiple Regression Analysis. The results and analysis indicated that there is a statistically significant impact of extrinsic variables on the motivation level of salesforce. In addition to this, it is also identified that increased level of motivation of sales force results in effective sales performance that leads towards effective process of organizational goals establishment.

Keywords: Challenge salesforce, Motivation, Organizational performance 


\section{Introduction}

\subsection{Research Introduction}

The pharmaceutical industry in Pakistan is a very demanding market that is always subject to competitive pressures. According to Sari, Bendesa, and Antara (2019) in order to survive it is necessary to keep employees dedicates and ready to make efforts for the growth and persistent performance of the company. Thus, as identified by Shin and Grant (2019) and Gross, Thaler, and Winter (2019) it is important to define strategies and objectives, overcoming the challenges of employees and in results remain competitive in the market.

In different scholarly resources, the motivation of the sales force has been presented as a central variable for the improvement of organizational growth and performance. Interest in the topic arises in the first quarter of the 20th century, when in which the Taylor model of scientific organization of work begins to be problematized and the importance of the "human factor" in organizations emerges. Since then, many investigations and theories have been developed with the aim of try to explain the functioning of this internal impulse that leads individuals to act depending on the achievement of certain objectives at individual as well as organizational levels.

Today, organizations are increasingly taking into account people's performance, not being considered just as simple resources, with the ability to reach the organization's goals. According to Roopai (2012) managing people is not simply controlling procedures and routines. It implies involvement of all members of the organization, and there is also a commitment to the part of the organization in teaching, motivating and investing in mechanisms that promote creativity and innovation, working as differentiating factors. Considering the importance of motivation for the employees for achieving individual and organizational goals, the current research study emphasizes exploring the impact of motivation of the employees working in sales team on the overall organizational performance.

\subsection{Research Background}

According to the research, it is identified that the pharmaceutical and healthcare industries in Pakistan are highly competitive and challenging. There are almost 600 pharmaceutical companies in Pakistan, and the main world leaders are in Pakistan. The industry offers many growth opportunities for pharmaceutical manufacturers, sales representatives, and pharmaceutical executives.

According to Obikeze (2016) pharmaceutical business growth in Pakistan represents an important element for the sustainability of the operations or transactions executed of a company. Therefore, for today's organizations, human capital is one of the most important elements that drive the economic development of companies.

It is for this reason that interest in conducting this research has emerged on the impact of motivation on the work performance of sales employees of the pharmaceutical companies. Therefore the sales force motivation and organizational work performance variables were determined, which constitute an important element that is present at any time in the field 
labor and the relationship between them is decisive to achieve the established organizational objectives, with efficiency and effectiveness by the human resource.

According to John and Weitz (1989) motivation towards employees is a mechanism implemented by organizations, in order that both parties, employee-employer, obtain a reciprocal benefit, that is, the employee receives a stimulus that allows efficiency in the development of activities assigned and the cost-benefit of the organization, is to get each of them to unify their skills and abilities to achieve the fulfillment of each of the goals previously established by the institution. On the other hand, organizational goal accomplishment is a factor which determines the effort of employees to reach those goals.

Through research, it is intended to raise awareness of the problem statement and the justification of the same, the related variables and the indicators of each, the applied methodology and the results obtained from it, as well as various theories that are fully related to that topic. Finally, it concludes with the results found in the investigation during the development of this process.

\subsection{Problem Statement}

Motivation can be a major player In turning the performance of the company from worst to good all we have to maneuver the front line soldiers (sales Rep) and bring forth their best performance to increase sales for such cases we intend to learn the impact of sales force motivation on organizational performance in pharmaceutical industry in Karachi.

\subsection{Aim of the Research}

This research objects to define the interaction (Intrinsic, Extrinsic) of motivational factors for the salesforce teams in pharmaceuticals with respect to company performance. It will test the relevance of modern motivation theories in their attempt to explain the importance of the determinants of motivation in the context of performance by the sales force in Karachi, Pakistan. The following are the objectives of this research.

- To identify the factors that help determine the motivation levels for sales representatives unique to the pharmaceutical sector in Karachi.

- To study the extrinsic \& intrinsic factors that influence the motivation of sales representatives.

- To test the impact on the motivation levels of the sales force in the pharmaceutical sector.

- To determine the methods of motivation acceptable to sales representatives.

- To identify the most useful technique that can be used to enhance the motivation levels of sales employees.

\subsection{Research Questions}

The purpose of this study is to investigate the sales force motivation factors and their influence on the performance of pharmaceutical syndicates in Karachi, Pakistan.

- Research Question 1: To study the impact of various factors on salesforce motivation and 
performance and its effect on pharmaceutical industry.

- Research Question2: To study the contribution of the pharmaceutical sales force on organizational goal accomplishment

\subsection{Research Hypothesis}

- H1: Extrinsic variables have a significant positive effect on salesforce motivation.

- Ho: Extrinsic variables do not have a significant positive effect on salesforce motivation.

- H2: Intrinsic variables have a significant positive effect on salesforce motivation.

- Ho: Intrinsic variables do not have a significant positive effect on salesforce motivation.

- H3: Salesforce motivation has significant positive effect on sales force performance.

- Ho: Salesforce motivation does not have a significant positive effect on sales force performance.

- H4: Moderating variable also affects organizational performance.

- Ho: Moderating variables does not affect organizational performance.

- H5: Salesforce performance contributes to organizational goal establishment.

- Ho: Salesforce performance contributes to organizational goal establishment.

\subsection{Significance of the Study}

This research study is significant because it serves as the basis for establishing the impact that sales force motivation has on the individual as well as organizational performance and with the results obtained it aims to benefit those involved (researchers, company, society) to make decisions that improve the productive capacity of the organization.

According to the notion delivered by John, Francis, and Innocent (2012) the motivational issue has a significant influence on the scope of the objectives of the company, also in the personal and professional growth of employees and this is seen reflected in the objectives accomplished by the organization. Therefore, because it is a topic that is present in the daily life of organizations and for being of great interest to sales forces, it has been decided to investigate this theme; and in this way companies implement strategies that stimulate the motivation level of employees and improving overall employee as well as organizational performance.

Parvin and Kabir (2011) indicated that for most organizations, the good performance of organization is dependent on the motivation level of employees since human capital constitutes an indispensable resource that allows achieves the objectives previously established inside and outside any organization. Mishra, Sahoo, and Sahoo (2012) indicated that an employee's poor performance caused by frustration and job dissatisfaction can result in problems such as poor customer service, poor sales performance, lack of security to work as well as generate an unstable work environment or context and inappropriate in which daily work cannot be developed. 
At present, it can be seen that pharmaceutical companies in Karachi emphasize the increase in sales for the market. Therefore, it is important for pharmaceutical companies to focus on optimizing the work performance of the employees. This research study signifies the importance of sales force motivation as not implementing this element lead to different problems arises. At the same time there is a significant problem regarding the achievement of goals proposed by management, since they are high and often not accessible to be reached, generating frustration and stress to the employee, this may be the result of the lack of implementation of motivational strategies by the command units, by for example, the lack of incentive plans to compensate the employee when he achieves achieve goals, demonstrating good work.

\subsection{Scope of the Study}

This study has a wide range of scope. Firstly, it deals with the issues in the pharmaceutical industry projects which are an important industrial sector for the development of Pakistan. Furthermore, it targets the pharmaceutical industries located in Pakistan. This research provides an overview of the issues and explorative analysis of sales rep performance in the pharmaceutical industry in Pakistan. Moreover, this research has practical managerial implications for managers that are related to human resource management and the company. This will assist firms in making a strategy to ensure that the identified issues do not influence sales anymore. These strategies will drastically improve the performance of managers and their teams in delivering the project within time. The industries that are contacted for this purpose belong to both the private and public sectors. Moreover, these industries are involved in making pharmaceutical components for serving the industrial and domestic requirements of medical and healthcare in Pakistan. The Pakistani pharmaceutical industry currently struggling to contribute significantly to the economy of Pakistan would be strengthened as the result of the strategies and recommendations based on the findings of this research. All the information presented in this research can be utilized for future research that can not only target Pakistani pharmaceutical industry but also other developing countries.

\subsection{Limitations of the Study}

This research work is limited to some restrictions that invite other researchers to conduct future research. This study was limited to time pressure. As a result, the total number of respondents surveyed is limited. Collecting multiple answers will take longer. In addition, this study included only consumers of pharmaceutical companies. Therefore, the results may not apply to other types of markets, stores, and other consumer environments. This study is also limited to purposive sampling strategies. Therefore, it cannot be assumed that results and results lead to conclusions about specific consumer characteristics. This can be considered under investigation for the future.

\section{Literature Review}

This chapter consists of a literature review that addresses theoretical concepts, classic and recent references on the study of the motivation of several authors in the area of research, their influence on the success of companies and some sales management tools. We consider it 
essential to present several theories of motivation on the subject under study. The main variables are motivational factors, motivation, sales force and performance.

\subsection{Theoretical Review}

\subsubsection{Motivation: Concept and Importance}

There are several definitions of motivation in the scientific literature. Some authors present motivation in a more abbreviated form, such as "the forces that act on and within the individual, that initiate and direct their behavior" (Sims, Fineman, \& Gabriel, 1993, p. 273). Others, however, extend into broader and more detailed definitions such as "the set of energetic forces that originate both in and out of the individual, and that shape work behavior, determining its shape, direction, intensity and duration" (Pinder, 1998, p. 11) or "the internal psychological forces of an individual that determine the direction of his behavior, his level of effort and his persistence in the face of obstacles" (George \& Jones, 1999, p. 183).

From the combination of the various definitions, the concept of motivation can be understood as the internal force or impulse that predisposes individuals to act towards an objective. It is an individual phenomenon, in that different people have different systems of values, attitudes, expectations and, therefore, different motivations. It is also considered as an intentional and voluntary phenomenon, which results from the cross interaction between the individual and the situation, thus denoting the individual and situational influence on the diversity of motivational states.

The literature on the motivational factors that influence the professional conduct of organizations is vast. Those factors can be classified in several ways, depending on the perspective analyzed. Bearing in mind that this will be a topic to be developed throughout the investigation, it is important to underline that, among the different classifications that aim to organize the diversity of approaches and theories, one of the most systematic is that it divides motivational theories from content and of process.

Defining the concept of motivation is not an easy task. In relation to its etymological origin, and according to Bergamini (2006, p. 31, emphasis added), motivation originally derives from the word movere, which means to move. Thus, it translates the idea of moving or moving from one place to another. In organizational terms, the motivation would thus be everything that leads the individual to adopt a certain behavior, to have certain attitudes and behaviors in the work environment.

There are several definitions in the literature; each author adopts a definition in line with his research. A comprehensive definition that is simple to understand defines motivation as a "set of energetic forces that originate both in and out of the individual, and which give rise to work behavior, determining its shape, direction, intensity, and duration." (Cunha et al., 2007, p. 154).

The study of motivation is based on the areas of psychology, but given its influence on the results and productivity of individuals, its study has been extended to the management and with increasing interest for researchers and organizations. It is sometimes confused by "inner 
states", with desires, feelings or states of mind (Boachie-Mensah \& Adu-Poku), and it is necessary not to vulgarize the theme of motivation and scientifically substantiate the concepts.

Several studies, which seek to explain the relationship between motivation and other organizational variables, have shown that motivation promotes behaviors that contribute to increasing individual and organizational effectiveness, such as effort, involvement with work, commitment, creativity, retention and performance (Gagné \& Deci, 2005; Islam \& Ismail, 2008; Mitchell, 1982).

Tavares (2011) defines motivation as the process of activating and directing behavior that aims to satisfy a need. Motivation is the complex of situational and organizational variables that explain the activity and orientation of the individuals' experience and behavior (Jorge \& Silva, 2000). For Cushway and Lodge (1993, p. 15) motivation is the set of stimuli that influence the individual's behavior in the organization and the degree of effort shown by the worker to achieve a certain end and objective.

According to Brugnera (2007, p, 12) "motivation is a force that puts us on the path to an objective". However, there is still a lot of confusion about this. Being on the way to an objective can be due to intrinsic or extrinsic factors. It is intrinsic when this force comes from within us, in which case there is motivation. However, when the factors are extrinsic, the strength comes from outside, and this is not really motivation but stimulus.

Junior (2008) argues that an individual cannot be motivated unless the essence of motivation comes from him. The seller has to want to reach and exceed his goals; and for your manager to motivate you to achieve your goals, self-motivation must exist. Motivation arises when a person seeks, consciously or unconsciously, to meet a physiological or psychological need.

Motivation is something personal, particular to each one, they are sets of needs, stimuli that lead to the achievement of the desired goal. In this way, it is worth mentioning that this process is not an easy task. It is possible to work on the motivational aspects of these individuals, because when they feel motivated, they chase their dreams, and contribute more to the company's productivity in addition to feeling like people fulfilled professionally and personally.

\subsubsection{Theories of Motivation}

Several formal theories have been developed to understand the differences between individual needs. We find some of the theories namely Maslow's Hierarchy of Needs, Alderfer's ERG Theory, Herzberg's Theory of Motivation and McClelland's Acquired Needs Theory. These theories of motivation are linked to unique individual needs. Since each individual is unique, motivational and personality profiles of the sellers' wills and behavior patterns were identified.

We present a brief summary in table 1 of contemporary theories of motivation. 
Table 1. Description of contemporary theories of motivation

\begin{tabular}{|c|c|c|}
\hline Theory & Author & Description \\
\hline Hierarchy of needs & $\begin{array}{l}\text { Abraham } \\
\text { Maslow }\end{array}$ & $\begin{array}{l}\text { Psychological, security, belonging, esteem and } \\
\text { self-realization are arranged in a hierarchy, from the least to } \\
\text { the most important. The individual goes up the hierarchy as a } \\
\text { need is substantially satisfied. }\end{array}$ \\
\hline ERG Theory & $\begin{array}{l}\text { Clayton P. } \\
\text { Alderfer }\end{array}$ & $\begin{array}{l}\text { Classifies needs hierarchically into needs of existence, } \\
\text { kinship and growth. Like Maslow, suggests that people focus } \\
\text { on more important as they satisfy the least important but, } \\
\text { unlike Maslow, he suggests that people focus on less } \\
\text { important needs if the most important needs are not met. }\end{array}$ \\
\hline Hygiene - & Frederick & Maintains that the intrinsic professional values (for \\
\hline motivation & Herzberg & $\begin{array}{l}\text { For example, stimulating work, achieving goals) motivate, } \\
\text { while extrinsic professional values (for example, payment) } \\
\text { only appease employees. }\end{array}$ \\
\hline $\begin{array}{l}\text { Theory of } \\
\text { Acquired Needs }\end{array}$ & $\begin{array}{l}\text { David } \\
\text { McClelland }\end{array}$ & $\begin{array}{l}\text { It suggests that there are three major professional needs: } \\
\text { fulfill goals, affiliation, and power. A greater need achieving } \\
\text { goals and affiliation has been linked to a better performance } \\
\text { of sales managers. }\end{array}$ \\
\hline Equity Theory & $\begin{array}{l}\text { J. Stacy } \\
\text { Adams }\end{array}$ & $\begin{array}{l}\text { Suggests that people evaluate how they are treated by } \\
\text { compared to "other relevant", and that motivation will suffer } \\
\text { if the treatment is noticeably uneven. }\end{array}$ \\
\hline
\end{tabular}

\section{1) Abraham Maslow's Hierarchy of Need's Theory}

Theories and explanatory models of human motivation began to be developed from the 1940s, with Abraham Maslow being the "father" of the first theory of motivation that, until today, is known by Maslow's hierarchy of needs theory (Jorge e Silva, 2000).

Maslow's theory is based on two assumptions, people are motivated by the desire to satisfy certain types of needs and these needs are universal and are organized in a sequential and hierarchical way. It distinguishes five levels of needs represented graphically by a pyramid (from bottom to top): physiological needs, security needs, social needs, esteem needs and self-realization needs. Maslow further divided needs into two groups: primary and secondary (Câmara et al., 1999).

The primary needs encompass the first two levels at the base of the pyramid, taking into account personal preservation and conservation. This includes physiological and security needs. According to Maslow, the needs commonly considered as the starting point of the motivation process are physiological needs (Maslow, 1954). These include elements such as food, clothing, housing or comfort and can be met essentially through salary and efficient working methods. Safety needs, as the name suggests, imply job security and stability as well as the defense of physical damage and risks. For them, seniority, insurance programs, and other benefits, safe working conditions and unionism play a fundamental role in meeting 
these needs. As can be seen, these types of needs are met externally, insofar as they are closely related to the organizational context and the working conditions to which the subject is attached.

Secondary needs, as they refer to socio-individual identity, are related to the top three levels (social needs, self-esteem, and self-fulfillment) and are understood to be those that are satisfied internally, that is, by the will and personal characteristics of the own individual. Once safety needs are satisfied and guaranteed, then the needs that the author calls social needs arise. This categorization refers, essentially, to factors such as affection, companionship, acceptance in the group or teamwork. In turn, through the possibility of exercising a greater degree of authority and the opportunity to participate in important decisions, the needs for self-esteem include the recognition of our personal abilities and the recognition of other people in relation to our ability to perform the functions to which they belong. Finally, the last level of the pyramid proposed by Maslow includes the needs for self-realization. These include feelings of independence and competence, as well as opportunities to do creative work and freedom to make decisions. This last level is the most difficult to satisfy and is summarized by the author as follows: "A musician must make music, an artist must paint, a poet must write if he is to be ultimately at peace with himself. What a man can be, he must be" (Maslow, 1954, p. 46).

\section{2) Frederick Herzberg's Two-Factor Theory}

Frederick Herzberg (1968) proposes a different perspective from the previous ones through the "Bifactorial Theory" or "Theory of Motivating and Hygienic Factors". For Herzberg, motivation depends on two types of factors: intrinsic (motivating factors, which promote job satisfaction) and extrinsic (hygienic factors, which prevent job satisfaction) (Herzberg, Mausner \& Snyderman, 1959; HesEspanhol, 2000).

Hygienic (extrinsic) factors encompass the entire work environment; constitute the work context that involves the worker, such as salary, working conditions, politics and organizational climate, supervision, interpersonal relations between employees. When these factors are fully offered, they do not lead to satisfaction but avoid dissatisfaction. On the contrary, when they are not offered in full, they lead to individual dissatisfaction. Because they are linked to dissatisfaction, they are also called unsatisfactory (Chiavenato, 2000).

Motivational factors (intrinsic) are related to the content of the position, the responsibility of the job, the possibility of growth, the type of task performed and the way it is performed. When these factors correspond to expectations, they generate satisfaction; on the contrary, if they are not offered optimally, they avoid satisfaction but do not cause dissatisfaction, which is why they are designated as satisfactory factors. They produce a lasting effect of satisfaction and increased productivity at levels of excellence (Chiavenato, 2000).

The motivational factors of Herzberg's theory are summarized in the following table: 
Table 2. Motivational factors of Herzberg's theory

\begin{tabular}{|c|c|}
\hline $\begin{array}{l}\text { Extrinsic or Hygienic Factors } \\
\text { (which produce dissatisfaction) }\end{array}$ & $\begin{array}{l}\text { Intrinsic or Motivational Factors } \\
\text { (which produce satisfaction) }\end{array}$ \\
\hline Company management policies & Realization \\
\hline Supervision & Recognition \\
\hline $\begin{array}{l}\text { Interpersonal relations with the boss, colleagues and / or } \\
\text { subordinates }\end{array}$ & Nature of the work itself \\
\hline Work conditions & Responsibility \\
\hline Salary & Possibility of promotion \\
\hline Personal life & Varied and challenging work \\
\hline Statute & Personal development \\
\hline Safety at work & Participation \\
\hline
\end{tabular}

Source: Motivational factors of Herzberg's theory Adapted from Herzberg (1968).

In order to increase motivation at work, Herzberg proposes job enrichment, which consists of "deliberately expanding the responsibility, objectives and challenge of the job tasks" (Chiavenato, 2000, p. 88).

The motivational factors take into account their effectiveness in motivating people to higher achievements, producing a lasting effect of satisfaction and productivity increase in levels of excellence. These are needs of a nature intrinsic to work, which obey a dynamic of growth and lead to satisfaction and happiness. They include the following needs: personal fulfillment / success, success, participation, recognition, development, growing responsibilities and challenging work (González-Cruz, Botella-Carrubi, \& Martínez-Fuentes, 2019).

In this context, the effect of motivating factors on people's behavior is, according to Herzberg (1974), more profound, stable and long lasting. It is in carrying out the task that the employee finds the way and means to develop his creativity, responsibility and independence, aiming to develop his performance in order to reach the maximum of his potential.

Herzberg (1974) highlights the relationship between its two classes of factors and the organizational environment, coming to the conclusion that motivational factors are above everything, related to the content of the work and the nature of the tasks to be performed by a given individual, are under his control, since they are related to what he does and performs and the hygienic factors are related to the context at work and have a preventive character, being able to avoid dissatisfaction (Miao, Eva, Newman, \& Schwarz, 2019). "The opposite of job satisfaction would not be dissatisfaction, but no job satisfaction; and, in the same way, the opposite of professional dissatisfaction would be no professional dissatisfaction and not satisfaction" (Chiavenato, 1997, p. 91). In this way, managers, if they want to motivate their employees, will have to try to satisfy motivational factors and if they simply want to have unsatisfied employees they will have to worry about hygienic factors.

3) Victor Vroom's Expectancy Theory 
Each person is a reality. People react in different ways, depending on the circumstances in which they are involved. Recognizing these differences, psychologist Victor Vroom, during the 1960s, developed a theory of motivation that excludes preconceived notions (Chiavenato, 1997). It is thus evident the challenge to the models presented by Maslow and Herzberg, whose theories are based on the presumption that there are stable ways to motivate employees, either through the pyramid of needs or through the enrichment of the position (Wright, Hassan, \& Christensen, 2017).

According to Vroom, quoted by Bilhim (1996, p. 269) "the motivation of individuals to exert effort is based on their expectations of success". For this reason, Vroom states that the motivation process must be explained according to the goals and choices of each individual, and must take into account the expectations of reaching those goals. This theory assumes that people are able to make intelligent and rational estimates of the consequences of a given choice and how these consequences will affect their own interests (Schwarz, Newman, Cooper, \& Eva, 2016).

This theory, which has Vroom as one of its main representatives, holds that the individual's conscious desires and expectations are more important than his unconscious impulses or needs. There would be a cognitive process with logical reasoning to make decisions where the individual ponders the sum of the valences and the probability of success and it is this process that determines the motivation (Martinez \& Paraguay, 2003).

Thus, Vroom's theory raises a previously unheard of question. It is necessary for the worker to feel able to achieve his personal goals (previously outlined) in order to feel motivated. This assumption ends up combining motivation with competence. It suggests that a worker who seeks self-realization through those goals will only feel motivated when he feels he is capable of achieving them (Belrhiti, Van Damme, Belalia, \& Marchal, 2019).

The organization of this theory is based on three fundamental concepts:

- The expectation or effort-performance relationship, which is the probability that a given action will lead to an ambitious result, provided that the means and skills for success are available. Greater effort will mean better performance;

- The valence or performance-reward relationship, which includes directing your preferences towards certain final results;

- The instrumentality or reward-personal goals relationship, which appears when the result allows and facilitates access to another result; for example, an administrative, student worker who invests in medical school, wants good monetary rewards, in that they can allow a lifestyle according to their social status needs (McCarthy, Wei, Homberg, \& Tabvuma, 2019).

Thus, for an employee to be motivated, he needs to value the result or the reward, he needs to believe that an additional effort will lead him to better performance and that the better performance will allow better results and consequent rewards (Ferreira, 2006).In this context, referring to Cunha et al. (2007, p. 171), people's level of motivation is dependent on the satisfaction of the following conditions: high valence, high instrumentality and high expectation. 


\subsubsection{SalesForce Management}

A research study conducted by Koh, Gammoh, and Okoroafo (2011) indicated that Salesforce is one of the most important elements in successful companies because they are the bridge between the company and customers. John, Francis, and Innocent (2012) contemplated that sales teams and their managers constitute a strong investment by companies and largely define the sources of business revenue. Many companies are beginning to understand that they achieve better performance from their teams by treating their Salesforce as an investment portfolio, which requires different types of attention (John, Francis, \& Innocent, 2012). The seller carries out a work with a unique nature, with varied activities and responsibilities, which gives him different experiences during the sale and the dual function of representing the company with the customer, but also representing the customer with the company, gives the company seller role, characteristics different from other works (Stanton and Spiro, 2000).

Naqvi (2019) and Sahoo, Routray, and Dash (2014) understand sales force as a group of individuals who have a direct responsibility to establish business transactions with current or potential customers whose most significant source of income comes from the sales they make. Chowdhury (2007) indicated that the management of the sales force is normally the responsibility of a marketing department, with sales managers as direct actors on the ground. The allocation of responsibilities varies from organization to size.

Related to management of sales force team, Wiese and Coetzee (2013) contemplated that a number of areas are part of the managers' tasks and competencies, ranging from the decision making of recruitment and selection of salespeople (marketing technicians) to direct monitoring on the ground by mediators, through the management of the counter, which ranges from the definition of tasks and functions of commercial assistants, responsibilities in taking risks of business until the generic technical-commercial training of the employees who are part of the branch.

\subsubsection{Salesforce and Motivation}

Malik and Naeem (2009) in a research study identified that company's pay incentives to Salesforce in order to keep them motivated in pursuing their goals. Salesforce, like the face of the company, requires different methods of incentives. Salespersons' roles have different characteristics from those of other employees of the company. As we have already seen, in general, they work outside the company's building, away from hierarchical superiors and work more isolated and autonomously. On the other hand, according to Malik Naeem, and Ahmad (2012) salespeople are subject to customer refusals and, therefore, must have a strong mental structure to not easily discourage. Thus, the methods of goal setting, control, and motivation and performance evaluation of salespeople are more rigorous and, at times, more demanding than those that applies to other functions.

According to Hameed, Dahri, Hayat, Hashmi, Haneef, and Qureshi (2018) for motivation plan to be effective, the sales manager must consider the core motivating factors of the salesperson. The various motivation methods that are identified, such as incentive campaigns, sales meetings and coaching activities, aim to act on the motivating factors. 
According to Klein (2019) and Van den Broeck, Carpini, and Diefendorf (2019). incentive campaigns generally take the form of contests, which results in the possibility of having access to different types of prizes, namely cash, in-kind (cars, travel, appliances, among others), parking space, shares or company obligations, commemorative medals or plaques and public recognition of merit (title of salesperson of the month in internal publications, lunch with company officials, etc.).

Galli (2020) contemplated that whatever the goals and prizes, the architecture of these contests should not induce salespeople to compete in isolation and selfishly against other teammates. The spirit of a contest should promote a competition that will lead each one to surpass him or to reach an ambitious sales objective, such as beating a competitor. The golden rules that ensure the success of an incentive campaign are: Regarding the methods of incentive to monetary awards, there are authors who consider that it can contribute to encouraging employees, but not be enough to motivate them. In the pharmaceutical sector, in the companies in our study there are other factors that contribute to the motivation of Salesforce, although the incentive premiums have a considerable weight.

\subsection{Empirical Review}

A research study conducted by Chowdhury (2007) identified the influence of the behavior of supervisors on the performance of salespeople and improving motivation level of salespeople. According to the notion delivered by Chowdhury (2007) it is identified that employees' motivation level is increased through effective engagement of supervisors with sales team endorsing positive behavior leading towards increased intrinsic motivation and performance of employees.

Another research study conducted by Sahoo, Routray, and Dash (2014) explores the factor affecting the selling performance of sales employees working in the pharmaceutical industry. According to the findings of the study it is identified that belongingness, ease of doing work, career perspective, freedom, internal environment, openness and no work pressure have significant impact on performance of salespeople working in pharmaceutical companies.

According to the resulting study executed by Koh, Gammoh, and Okoroafo (2011) it is identified motivation has been considered as one of the important aspects of the performance of salesforce. It is identified by the authors that for the employees working in insurance industry, aspects like cultural values, organizational work setting, and personal variables are important for affecting motivation level of the employees. In addition to this, gender and marital differences are also important factors that moderate the process of motivating employees.

Research conducted by Mensah and Poku (2016) focuses on the companies operating in insurance industry. This research explores the components used by the companies to execute their sales job in an effective and efficient way. According to the findings of the study, it is identified that promotion opportunity, recognition, job security and role clarity are important factors that contribute towards the increased level of motivation among sales forces.

Another research study conducted by John, Francis, and Innocent (2012) explored the 
influence of sales force motivation on the performance of salespeople. According to the results of the study, it is identified that financial rewards influence the motivation level of salesforce. In addition to this, meeting and effective communication among salespeople and sales managers results in increased performance of sales teams. According to John, Francis and Innocent (2012), it is important for managers working in pharmaceutical companies to make behavioral and structural adjustments to motivate employees in sales teams.

Mishra, Kumar Sahoo, and Sahoo (2012) in a research study concluded that salesperson performance is the contribution towards achieving company goals. According to the authors, it is identified that achieving sales performance is dependent on motivation and commitment level of the sales force. This level of aggressiveness will appear from how active salespeople identify potential customers, the orientation is to always have a high income, and the motivation is to always sell by exceeding sales targets and profitably.

In addition to this, John and Weitz (2010) to achieve optimum performance, the salesperson must disperse existing obstacles related to leadership quality, communication quality and the application of justice between supervisors and salespeople. According to Weitz (2010), salespeople must have the ability to identify who customers visit, what is the frequency of visits, what are conducted during the visit and what support is needed to succeed the sale. By fulfilling these factors, it will give impact the successful implementation of the task (Wilson 1993, p. 6).

Furthermore, Ansoglenang, Thompson, and Awugah (2019) say that the job of the sales force is always dealing with customers because of that knowledge and ability opening networks with customers is a strategy to deliver the company's success. Lee and Bong (2019) explain that to achieve the performance of the sales force then the development of selling skills will help them be able to plan take advantage of opportunities, be able to negotiate and have the ability to build competence.

Job satisfaction is one of the important motivating factors, and the value of motivation related to this factor varies from person to person. Mugasa (2013) found in a study that motivation has a positive impact on employee performance. Research shows that motivation can improve job performance, maintain solidarity between employees and employers, and produce quality products and employees. Motivation also promotes the confidentiality and punctuality of sales staff.

The current changing sales environment is much more complex and requires significant changes to performance statistics, goals, controls and compensation. Okey (2012) conducted a study to study the comparative impact on salesperson incentives in production and service companies. The results did not show significant differences in the level of motivation of the sales teams of the production and service companies. Supplementary allowances over the phone, fuel surcharges, food stamps, roaming/travel allowances and transportation benefits have proven to be current means of motivating sales teams.

The important function of a sales representative is to achieve sales objectives and build and maintain good customer relationships. Based on a study by Roopai (2012), the study used 
Herzberger's theory of motivation and hygiene to assess the job satisfaction of drug sales representatives. Respondents were generally satisfied with their work. Satisfaction with working conditions, work itself and recognition is higher. It was discovered that "working conditions" were the best predictors of overall job satisfaction, followed by safety and responsibility at work.

\subsection{The Gap in the Literature}

The review of the current literature enables the researcher to explore and assess the significance of motivation of employees and its impact on the individual as well as organizational performance of the companies. In addition to this, a review of the literature also sheds light on the sales force performance and the factors affecting the performance of salespeople. However, there exist some limitations that are observed in the current literature that can be fulfilled through exploring the impact of sales force motivation on organizational performance with respect to pharmaceutical industry operating in Karachi.

\subsection{Summary}

This section of the study identified diverse scholarly resources related to employee motivation and performance of the organization. A comprehensive theoretical review discussed different theories related to motivation and sales performance. Moreover, a comprehensive empirical review emphasized identifying the literature related to studies conducted within the understudied phenomenon. The next chapter of the study emphasized identifying the methods and techniques used for the execution of the current research.

\section{Research Methodology}

Chapter 3 of research involves the chapter of methodology which focuses on the tools, techniques and instruments of the research. The instruments and philosophies used by the researcher for the present study are discussed in this chapter. This chapter describes the rationale of specific procedures and techniques in order to identify select and analyze the data of the research. This section identifies the main questions asked by the researcher in order to gather data. It involves the design, philosophy and approaches of the study. The methodology is used for the basic understanding of the tools and techniques used by the researcher in order to extract the end result. Therefore the research methodology identifies and examines the tools and techniques in terms of approaches, research strategy, research design and research philosophy. The chapter also involves the techniques of data analysis and its plan, justification of methods and also involves the limitation of the research method. Moreover, the sources of the data and its sample size are also identified in this chapter. The methodology also involves the ethical considerations which researcher keeps in focus during the research. The chapter also involves conclusion in the end which includes a brief summary of the chapter.

\subsection{Research Purpose}

The primary purpose of research has three types which are exploratory, descriptive and explanatory. When the initial research begins on hypothetical and theoretical situations. The 
research in which it arranges the ground level information for future work and helps us to find out such problems and areas which have not been examined before, this type of research is known as exploratory. After setting the groundwork we need more information to explore the newly explored area we use descriptive research. It is conducted to find out more information about the study and give quality and standard to facts which are under observation but the reason for happing of an event is not determined by this research. We also used explanatory research which occurs after the exploratory and descriptive research, it was attempted to find out clear vision about the reason of occurrence of events and give understanding regarding the connection between variable. Also tells the impact of change and measure the changes on another variable

\subsection{Research Design}

Research approach, research design, and research question are all between associated. Research Design gives bits of knowledge something more than the sort of information is utilize - it alludes to general introduction to investigate and the kind of cases that are made for the research study. Research papers can be founded on either quantitative or qualitative information, or on a mix of both. How analysts select this may rely upon inclinations and capacities, and the reasonableness of specific ways to deal with research subject. However researchers should have the capacity to legitimize the reasons for utilizing such information.

Quantitative research is usually connected with the positivist research paradigm.

It usually includes data collection and modifying in the numeric form so that numeric calculations can be configured and researchers can make logical and coherent conclusions. On the other hand qualitative research is the research design is related to social constructivist paradigm that generally focuses the socially developed nature of reality. It is tied in with recording, breaking down and endeavoring to reveal the more reflective importance of human behavior and experience, including conflicting convictions, practices and feelings. Research analysts are keen on picking up a rich and complex comprehension of individuals' involvement and not in getting data which can be summed up to other larger gatherings (Buchanan \& Bryman, 2009).

For the execution of the current research and catering to the research questions in an effective manner, researcher opts for quantitative research design. The reason behind selecting quantitative research design is exploring the impact of independent variables on the dependent variable that largely involves numerical statistics. The quantitative research design will help researcher to identify conclusive notions from the available data through executing statistical tests.

\subsection{Sampling Design}

In consideration of this research, sampling is a process that is used in the statistical analysis where a predetermined number of observations is selected from a larger population. The study of Katz (2015) depicted that researchers usually could not make direct observations of every individual in the population who were taken to conduct the study. Instead, research requires specific data collection from a subset of individuals (sample) that could later use for 
making inferences about the entire population. In this research, the study has followed a non-probability sampling technique, which refers to selecting the elements (participants) based on their availability. In such scenario, the participants are difficult to reach, or researcher has personal judgments about the selection of the study population. In non-probability sampling, the research has emphasized using the purposive technique, which is selected based on the characteristics of a population as well as research objective of the study. Since in this research the targeted study population is already chosen (due to the nature of the study), rherefore, purposive sampling fits well with the situation.

In accordance with purposive sampling, it also refers to the subjective, selective, and judgmental sampling that specifically used when it comes to the selection of the particular group of individuals, cases, pieces of data or organization (Mackey \& Gass, 2015).

\subsection{Sample Size and Target Population}

In this research, the study has focused on selecting the population who belong only from the industry of pharmaceutical companies operating in Karachi. After selecting the sampling technique, it is necessary to define and explore a sampling size. According to Flick (2014), sample size determination is the act of choosing the replicates or number of observations that should be included in a statistical sample. In this research, the sample size is taken as a significant feature that aims to make inferences about a population from a sample. Since the study is based on quantitative research; therefore, the sample size selected is based on 200 participants belonging from only pharmaceutical-based organizations. The large sample size is chosen for the survey technique because it helps in generating more comprehensive framework as well as support in comparison and contradiction in generated information, easily and effectively.

\subsection{Types and Sources of Data Collection}

The research is based on using the primary method that involves collecting data or information directly from the real world. In this current study, the research has particularly contacted the individuals from the respective research field where employees from pharmaceutical companies are selected to acquire the information on salesforce motivation. The primary research is selected because it helps in targeting the issues more specifically than the secondary research as well as research has full control on the process of data collection. In addition, primary research also helped in fulfilling the objectives more competently $\mathrm{n}$ consideration of the research goal or scope (Katz, 2015). Embracing primary research also supported keeping the core emphasis on factors affecting motivation level of sales team members rather than focusing on the broader field of sales management. On the other hand, primary research is also chosen because data interpretation process is easier and more flexible as researcher knows about the needs and requirements of the research. Additionally, data availability is based on recent data or information rather than the prior evidence.

As discussed in the above statement, Hussein (2015) also denoted that secondary data usually involve information about previous years, which might not be useful and influence the credibility of the research's outcomes. Thus, primary data becomes a more reliable tool in avoiding irrelevant information and getting the information. Additionally, the proprietary 
issue is another significant factor that enables it to use the primary research approach. In primary methodology, no information can be easily shared with competitors or other companies. However, at the same time, the research has significantly faced certain limitations regarding utilizing the primary research only. Some of the major limitations that restrict the quality of research outcomes include (a) motivation (b) theories of motivation, (c) sales force motivation and (d) a huge number of resources are required to obtain the relevant information.

\subsection{Instrument}

The design of questionnaire will initiate from the demographic info to motivational factors like Intrinsic variables (Team planning, Responsibility, achievements, development programs), Extrinsic variables (Salary, Medical, Bonus, accommodation) along with the mediating variables and ending with company factor of performance questions.

\subsection{Methods of Data Analysis}

For this study, data is analyzed by means of statistical tests and quantitative strategies. Primary data collected through the survey process is analyzed by Multiple Regression Analysis and Pearson Correlation with SPSS. Opinions were also exchanged on the results of the regression test and the correlation test to support the research questions and to respond appropriately to the research questions.

\subsection{Ethical Considerations}

Ethical considerations are important events that define a moral protection plan that protects the right to investigate the use of research (Bryman, \& Bell, 2015). The following behavior patterns will be taken into account in order to ensure that the recruitment process and the data collection process are ethical at the request of this research study.

Autonomy: This basic ethical principle encompasses the legal and ethical direction of information gathering. In addition, voluntary participation is also necessary when participants give information about the risks and benefits of contributing to the collection process.

Beneficence: This means that researchers must be committed to increasing the benefits of those involved in the research process and committed to increasing the benefits of the whole community. In this research, the researcher is determined to make important decisions that can be made in the advertising and marketing field.

Confidentiality: This ethical rule of law covers the privacy and integrity of the participants involved in the interviews. According to this principle, the investigator must obtain personal data with the approval of the participants by the authorization of the concerned review board.

\subsection{Summary}

This section of the study identifies the methods, techniques and approaches used for executing the current research work. It is identified in this chapter that current research work is executed through quantitative research approach collecting data through survey questionnaires and analyzing using SPSS statistical tests. 


\section{Findings and Analysis}

Considering the importance of motivation for the employees for achieving individual and organizational goals, the current research study emphasizes exploring the impact of motivation of the employees working in sales team on the overall organizational performance. In this research work, researcher intends to identify the factors that help determine the motivation levels for sales representatives unique to the pharmaceutical sector in Karachi. The research study explores the most useful technique that can be used to enhance motivation levels of sales employees. In this section of the research study, the statistical analysis of the collected data is represented by using tabular and graphical representation. Following research questions are addressed in order to execute this chapter:

- Research Question 1: What is the impact of various factors on salesforce motivation and performance and its effect on pharmaceutical industry?

- Research Question2: What is the contribution of the pharmaceutical sales force on organizational goal accomplishment?

This section of the research included mainly two parts that are the statistical results of the collected data and the evaluation of the data. The previous chapter of the research identified the methodology that is used in order to accomplish systematic execution of the study. The researcher in this section of the study utilized different statistical tests that assist in identifying conclusive and coherent results. Reliability analysis is executed with the initiation of the chapter. Moreover, researcher also integrates demographic information analysis of the respondents who participated in the process of data collection. Descriptive analysis is also included in this chapter along with regression and correlation analysis. Regression analysis is executed for the criterion and predictor variables. All these statistical tests are executed with the help of SPSS that leads to the execution of testing the hypothesis of the research study. Following research hypothesis are set according to the set research questions:

- H1: Extrinsic variables have a significant positive effect on salesforce motivation.

- H2: Intrinsic variables have a significant positive effect on salesforce motivation.

- H3: Salesforce motivation has significant positive effect on salesforce performance.

- H4: Moderating variables also affect organizational performance.

- H5: Salesforce performance contributes to organizational goal establishment.

Moreover, this section of the research study also includes results in the tabular and graphical form that are interpreted with an in-depth analysis. At the end of this section, researcher executed a discussion related to the results with a concise conclusion.

\subsection{Reliability Analysis}

Reliability is the consistency of a series of measurements or a set of measuring instruments. It can be the measurement of the same measuring instrument (test with retest) will give the same result, or for a more subjective measurement, whether two assessors give similar scores 
(reliability between assessors). Reliability is not the same as validity. This means that reliable measurements will be consistent, but not necessarily measured. It is expected that research will be consistent with delivering consistent results for the same measurements. Repeated measurements are unreliable if they give different results. High reliability is empirically displayed with a number. The general agreement on reliability is $\geq 0.00$. Alpha> 0.7 means sufficient reliability, but if alpha> 0.80 has all the reliable objects, then all tests are consistently reliable. Or, there is a rule like this:

If the alpha value is $>0.90$, then reliability is excellent. Between 0.70 and 0.90 , reliability is high. If alpha is $0.50-0.70$ then reliability is moderate. If alpha is $<0.50$, the reliability is low. If alpha is low, the risk is that one or more things are not reliable. Cronbach's alpha is a measure of internal consistency that is, how closely related to a series of articles. A "high" alpha value is usually used as proof of the basic (or hidden) object of the structure (along with important arguments and possibly other statistical actions). However, a high alpha does not mean that the measure is one-dimensional. If you want to measure internal consistency, you can prove that your scale is one-dimensional and that more analysis can be done. Exploratory Factor Analysis is one of the methods of controlling dimensions. Technically, Cronbach's alpha is not a statistical test - it's a reliability coefficient (or coherence).

The following tables depict the reliability statistics of the items that were included in the questionnaire. According to the results, there were total 200 respondents who participated in the survey process. Moreover, Cronbach's alpha value for 30 total items included in the research is identified as 0.076 . According to rule, alpha value lies within the range of 0.70 to 0.90 , which indicates that there exists high reliability and internal consistency within the item of the questionnaire.

Table 3. Case processing summary

\begin{tabular}{llll}
\hline & & $\mathbf{N}$ & $\mathbf{\%}$ \\
\hline Cases & Valid & 200 & 100.0 \\
& Excludeda & 0 & .0 \\
& Total & 200 & 100.0 \\
\hline
\end{tabular}

Table 4. Reliability statistics

\begin{tabular}{ll}
\hline Cronbach's Alpha & N of Items \\
\hline $\mathbf{. 0 7 6}$ & 30 \\
\hline
\end{tabular}

\subsection{Respondents Profile}

In the process of survey and data collection, total of 200 respondents participated. According to the results for demographic and sample characteristics questions, it is identified that a total of 200 respondents participated. 
Table 5. Statistics

\begin{tabular}{lllllll}
\hline \multirow{2}{*}{$\mathbf{N}$} & & Gender & Age & Education & Experience & Designation \\
\cline { 2 - 7 } & Valid & 200 & 200 & 200 & 200 & 200 \\
& Missing & 0 & 0 & 0 & 0 & 0 \\
\hline
\end{tabular}

Among 200 respondents, 172respondents participated in the process of data collection were male and 28 respondents were female respondents. According to the majority of the results of the respondents who participated in the survey were from male gender.

Table 6. Gender

\begin{tabular}{llllll}
\hline Valid & & Frequency & Percent & Valid Percent & Cumulative Percent \\
\cline { 2 - 5 } & Male & 172 & 86.0 & 86.0 & 86.0 \\
& Female & 28 & 14.0 & 14.0 & 100.0 \\
& Total & 200 & 100.0 & 100.0 & \\
\hline
\end{tabular}

According to the results generated, it is identified that the respondents participated in the survey process were belong to different age group. 48 of the respondents were from the age of 20 to 30, 35 of the respondents were from the age group 31 to 40, 53 respondents indicated that they were of 41 to 50 years. 27 of the respondents were from the age group 51 to 60.37 of the respondents were above 60 . Results indicated that selection of the respondents was on a random basis that included respondents with diversified backgrounds.

Table 7. Age

\begin{tabular}{llllll}
\hline & & Frequency & Percent & Valid Percent & Cumulative Percent \\
\hline Valid & $20-30$ & 48 & 24.0 & 24.0 & 24.0 \\
& $31-40$ & 35 & 17.5 & 17.5 & 41.5 \\
& $41-50$ & 53 & 26.5 & 26.5 & 68.0 \\
& $51-60$ & 27 & 13.8 & 13.8 & 81.8 \\
& Above 60 & 37 & 18.3 & 18.3 & 100.0 \\
& Total & 200 & 100.0 & 100.0 & \\
\hline
\end{tabular}

Respondents were asked to inform about their education level. According to the results, 59 respondents indicated that they were matriculated, 39 stated that they have passed intermediate, 63 stated that they are graduated and 39 identified that their education was till post-graduation.

Table 8. Education

\begin{tabular}{|c|c|c|c|c|c|}
\hline & & Frequency & Percent & Valid Percent & Cumulative Percent \\
\hline \multirow[t]{5}{*}{ Valid } & Matriculation & 59 & 29.5 & 29.5 & 29.5 \\
\hline & Intermediate & 39 & 19.5 & 19.5 & 49.0 \\
\hline & Graduation & 63 & 31.5 & 31.5 & 80.5 \\
\hline & Post-Graduation & 39 & 19.5 & 19.5 & 100.0 \\
\hline & Total & 200 & 100.0 & 100.0 & \\
\hline
\end{tabular}




\section{Macrothink}

Another question that was asked by the respondents was about their year of working experience in the pharmaceutical industry. According to the findings, it is identified that total 60 respondents were working for 0 to 2 years in pharmaceutical industry. Moreover, 56 respondents were working in pharmaceutical industry for three to five years. Likewise, it is identified that 49 respondents were working in pharmaceutical industry for six to nine years. Total 35 respondents identified that they have experience of more than ten years of working in pharmaceutical industry.

Table 9. Experience

\begin{tabular}{llllll}
\hline & Frequency & Percent & Valid Percent & Cumulative Percent \\
\hline Valid & 0 to 2 years & 60 & 30.3 & 30.3 & 30.3 \\
& 3 to 5 years & 56 & 28.0 & 28.0 & 58.3 \\
& 6 to 9 years & 49 & 24.5 & 24.5 & 82.8 \\
& More than ten years & 35 & 17.3 & 17.3 & 100.0 \\
& Total & 200 & 100.0 & 100.0 & \\
\hline
\end{tabular}

\subsection{Results and Analysis}

\subsubsection{Hypothesis Testing}

In this hypothesis testing, the purpose was to find out the relationship between independent variable and a dependent variable (same or different). The purpose of the hypothesis was to test the relationship between different variables according to the following research model:

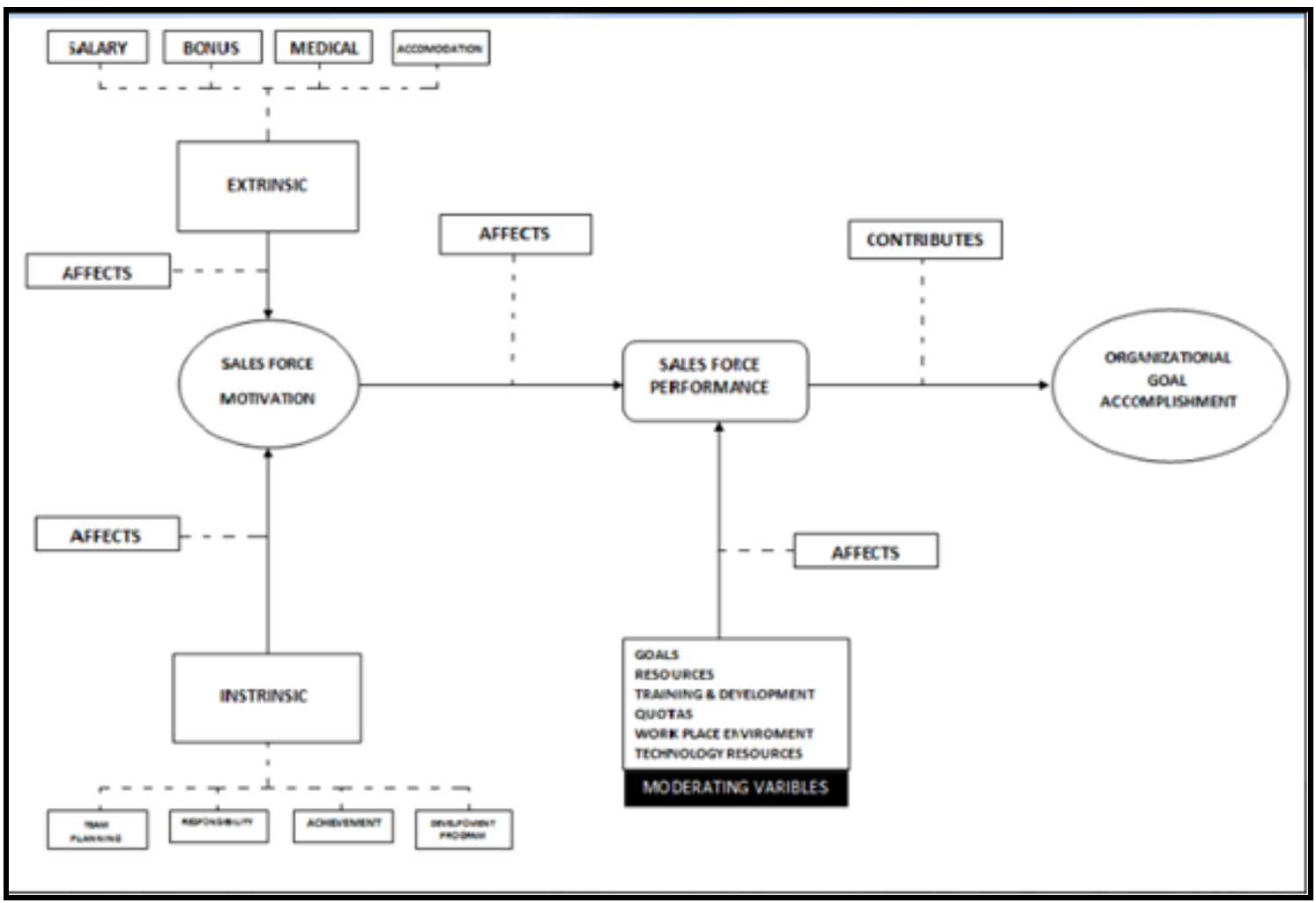




\subsubsection{Regression Analysis of Hypothesis 1}

The first hypothesis of the research focused on exploring the impact of extrinsic variables on the motivation level of the sales staff.

- $\mathrm{H}_{1}$ : Extrinsic variables have a significant positive effect on salesforce motivation.

- $\mathrm{H}_{\mathrm{o}}$ : Extrinsic variables do not have a significant positive effect on salesforce motivation.

A linear regression analysis was executed to test the hypothesis that indicates the following results:

Model Summary

\begin{tabular}{lllll}
\hline Model & R & R Square & Adjusted R Square & Std. The error of the Estimate \\
\hline $\mathbf{1}$ & $0.659^{\mathrm{a}}$ & 0.825 & -0.027 & 1.52531 \\
\hline
\end{tabular}

a. Predictors: (Constant), extrinsic variables

ANOVA

\begin{tabular}{lllllll}
\hline & Model & Sum of Squares & df & Mean Square & F & Sig. \\
\hline $\mathbf{1}$ & Regression & 5.663 & 5 & 1.133 & 0.487 & $0.000 \mathrm{~b}$ \\
& Residual & 218.697 & 94 & 2.327 & & \\
& Total & 224.360 & 99 & & & \\
\hline
\end{tabular}

a. Dependent Variable: sales force motivation

b. Predictors: (Constant), extrinsic variables

Coefficients $^{\mathrm{a}}$

\begin{tabular}{lllllll}
\hline \multirow{2}{*}{ Model } & \multicolumn{2}{l}{$\begin{array}{l}\text { Unstandardized } \\
\text { Coefficients }\end{array}$} & $\begin{array}{l}\text { Standardized } \\
\text { Coefficients }\end{array}$ & t & Sig. \\
\cline { 3 - 5 } & $\mathrm{B}$ & Std. Error & Beta & & \\
\hline $\mathbf{1}$ & (Constant) & 2.668 & 0.745 & & 3.582 & 0.001 \\
& Extrinsic Variables & 0.047 & 0.138 & 0.036 & .343 & 0.002 \\
\hline
\end{tabular}

a. Dependent Variable: sales force motivation

In the regression analysis presented above, the results go in support of the first hypothesis. The significance value of less than 0.05 identified that the extrinsic variables in the pharmaceutical industry of Karachi contribute towards influencing sales force motivation. A positive value of risk factors coefficient (.036) also shows a positive relationship between the variables. From the analysis above, it can be noticed that coefficients are positively related to each other, with the significance value 0.002 that is less than 0.05 ; therefore rejecting the null hypothesis. It is identified that extrinsic variables have a significant positive effect on salesforce motivation.

\subsubsection{Regression Analysis of Hypothesis 2}

The second hypothesis of the research focused on exploring the impact of intrinsic variables 
on the motivation level of sales staff.

- $\mathrm{H}_{2}$ : Intrinsic variables have a significant positive effect on salesforce motivation.

- $\mathrm{H}_{\mathrm{o}}$ : Intrinsic variables do not have a significant positive effect on salesforce motivation.

A linear regression analysis was executed to test the hypothesis that indicates the following results:

Model Summary

\begin{tabular}{lllll}
\hline Model & R & R Square & Adjusted R Square & Std. The error of the Estimate \\
\hline $\mathbf{1}$ & $0.470 \mathrm{a}$ & 0.921 & 0.215 & 0.562863 \\
\hline
\end{tabular}

a. Predictors: (Constant), intrinsic variables

\begin{tabular}{lllllll}
\multicolumn{7}{c}{ ANOVA } \\
\hline & Model & Sum of Squares & df & Mean Square & F & Sig. \\
\hline $\mathbf{1}$ & Regression & 13.32071 & 5 & 13.32071 & 42.04576 & $0.062 \mathrm{~b}$ \\
& Residual & 46.88856 & 94 & 0.316815 & & \\
& Total & 60.20927 & 99 & & & \\
\hline
\end{tabular}

a. Dependent Variable: sales force motivation

b. Predictors: (Constant), intrinsic variables

Coefficients $^{\mathrm{a}}$

\begin{tabular}{|c|c|c|c|c|c|c|}
\hline & \multirow[t]{2}{*}{ Model } & \multicolumn{2}{|c|}{$\begin{array}{l}\text { Unstandardized } \\
\text { Coefficients } \\
\end{array}$} & \multirow{2}{*}{$\begin{array}{l}\text { Standardized } \\
\text { Coefficients } \\
\text { Beta }\end{array}$} & \multirow[t]{2}{*}{$\mathbf{t}$} & \multirow[t]{2}{*}{ Sig. } \\
\hline & & $\mathrm{B}$ & Std. Error & & & \\
\hline \multirow[t]{2}{*}{1} & (Constant) & 1.856477 & 0.181037 & & 10.25469 & 0.001 \\
\hline & Intrinsic Variables & & 0.076998 & 0.024 & 1.619634 & 0.071 \\
\hline
\end{tabular}

a. Dependent Variable: sales force motivation

In the regression analysis presented above, the results go in support of the second hypothesis. The significance value of greater than 0.05 identified that the intrinsic variables in the pharmaceutical industry of Karachi do not contribute towards influencing sales force motivation. A positive value of coefficient (0.024) also shows a positive relationship between the variables. From the analysis above, it can be noticed that coefficients are positively related to each other, with the significance value 0.0071 that is greater than 0.05 ; therefore rejecting the alternative hypothesis. It is identified that intrinsic variables do not have a significant positive effect on salesforce motivation.

\subsubsection{Regression Analysis of Hypothesis 3}

The third hypothesis of the research focused on exploring the impact of sales force motivation on the sales force performance. 
- $\mathrm{H}_{3}$ : Salesforce motivation has significant positive effect on salesforce performance.

- $\mathrm{H}_{\mathrm{o}}$ : Salesforce motivation does not have significant positive effect on sales force performance.

A linear regression analysis was executed to test the hypothesis that indicates the following results:

Model Summary

\begin{tabular}{lllll}
\hline Model & R & R Square & Adjusted R Square & Std. The error of the Estimate \\
\hline $\mathbf{1}$ & 0.321 & 0.103 & 0.097 & 0.603878 \\
\hline
\end{tabular}

a. Predictors: (Constant), Salesforce motivation

ANOVA

\begin{tabular}{lllllll}
\hline & Model & Sum of Squares & df & Mean Square & F & Sig. \\
\hline $\mathbf{1}$ & Regression & 6.238312 & 5 & 6.238312 & 17.10679 & $0.000 \mathrm{~b}$ \\
& Residual & 53.97096 & 94 & 0.364669 & & \\
& Total & 60.20927 & 99 & & & \\
\hline
\end{tabular}

a. Dependent Variable: sales force performance

b. Predictors: (Constant), Salesforce motivation

Coefficients $^{\mathrm{a}}$

\begin{tabular}{lllllll}
\hline \multirow{2}{*}{ Model } & \multicolumn{2}{l}{$\begin{array}{l}\text { Unstandardized } \\
\text { Coefficients }\end{array}$} & $\begin{array}{l}\text { Standardized } \\
\text { Coefficients }\end{array}$ & t & \multirow{2}{*}{ Sig. } \\
\cline { 3 - 5 } & & B & Std. Error & Beta & \\
\hline $\mathbf{1}$ & (Constant) & 1.667441 & 0.143729 & & 11.60133 & 0.002 \\
& Sales force motivation & 0.262019 & 0.06335 & 0.020 & 4.136036 & 0.000 \\
\hline
\end{tabular}

a. Dependent Variable: sales force performance

In the regression analysis presented above, the results go in support of the third hypothesis. The significance value of less than 0.05 identified that the sales force motivation in the pharmaceutical industry of Karachi contribute towards influencing sales force performance. A positive value of coefficient (.020) also shows a positive relationship between the variables. From the analysis above, it can be noticed that coefficients are positively related to each other, with the significance value 0.000 that is less than 0.05 ; therefore rejecting the null hypothesis. It is identified that sales force motivation has a significant positive affect with sales force performance.

\subsubsection{Regression Analysis of Hypothesis 4}

The fourth hypothesis of the research focused on exploring the impact of moderating variables on organizational performance.

- $\mathrm{H}_{4}$ : Moderating variables also affect organizational performance. 
- $\mathrm{H}_{\mathrm{o}}$ : Moderating variables does not affect organizational performance.

A linear regression analysis was executed to test the hypothesis that indicates the following results:

Model Summary

\begin{tabular}{lllll}
\hline Model & R & R Square & Adjusted R Square & Std. The error of the Estimate \\
\hline $\mathbf{1}$ & $0.456 \mathrm{a}$ & 0.735 & 0.036 & 1.22335 \\
\hline
\end{tabular}

a. Predictors: (Constant), Moderating variable

ANOVA

\begin{tabular}{lllllll}
\hline & Model & Sum of Squares & df & Mean Square & F & Sig. \\
\hline $\mathbf{1}$ & Regression & 1.772135 & 5 & 1.772135 & 2.463 & $0.000 \mathrm{~b}$ \\
& Residual & 99.98268 & 94 & 0.675559 & & \\
& Total & 101.7548 & 99 & & & \\
\hline
\end{tabular}

a. Dependent Variable: organizational performance

b. Predictors: (Constant), Moderating variable

Coefficients $^{\mathrm{a}}$

\begin{tabular}{|c|c|c|c|c|c|c|}
\hline & \multirow[t]{2}{*}{ Model } & \multicolumn{2}{|c|}{$\begin{array}{l}\text { Unstandardized } \\
\text { Coefficients }\end{array}$} & \multirow{2}{*}{$\begin{array}{l}\text { Standardized } \\
\text { Coefficients } \\
\text { Beta }\end{array}$} & \multirow[t]{2}{*}{$\mathbf{t}$} & \multirow[t]{2}{*}{ Sig. } \\
\hline & & B & Std. Error & & & \\
\hline \multirow[t]{2}{*}{1} & (Constant) & 1.904608 & 0.195625 & & 9.735994 & 0.000 \\
\hline & Moderating variables & 0.139652 & 0.086225 & 0.025 & 1.619634 & 0.000 \\
\hline
\end{tabular}

a. Dependent Variable: organizational performance

In the regression analysis presented above, the results go in support of the first hypothesis. The significance value of less than 0.05 identified that the extrinsic variables in the pharmaceutical industry of Karachi contribute towards influencing sales force motivation. A positive value of risk factors coefficient (.025) also shows a positive relationship between the variables. From the analysis above, it can be noticed that coefficients are positively related to each other, with the significance value 0.000 that is less than 0.05 ; therefore rejecting the null hypothesis. It is identified that the moderating variable also affects organizational performance.

\subsubsection{Regression Analysis of Hypothesis 5}

The last hypothesis of the research focused on exploring the impact of Salesforce performance on the organizational goal establishment.

- $\mathrm{H}_{5}$ : Salesforce performance contributes to organizational goal establishment.

- $\mathrm{H}_{\mathrm{o}}$ : Salesforce performance contributes to organizational goal establishment. 
A linear regression analysis was executed to test the hypothesis that indicates the following results:

Model Summary

\begin{tabular}{lllll}
\hline Model & R & R Square & Adjusted R Square & Std. The error of the Estimate \\
\hline $\mathbf{1}$ & $0.659 \mathrm{a}$ & 0.825 & -0.027 & 1.52531 \\
\hline
\end{tabular}

a. Predictors: (Constant), Salesforce performance

ANOVA

\begin{tabular}{lllllll}
\hline & Model & Sum of Squares & df & Mean Square & F & Sig. \\
\hline $\mathbf{1}$ & Regression & 5.663 & 5 & 1.133 & 0.487 & $0.000 \mathrm{~b}$ \\
& Residual & 218.697 & 94 & 2.327 & & \\
& Total & 224.360 & 99 & & & \\
\hline
\end{tabular}

a. Dependent Variable: organizational goal establishment

b. Predictors: (Constant), Salesforce performance

Coefficients $^{\mathrm{a}}$

\begin{tabular}{lllllll}
\hline \multirow{2}{*}{ Model } & \multicolumn{2}{l}{$\begin{array}{l}\text { Unstandardized } \\
\text { Coefficients }\end{array}$} & \multicolumn{2}{l}{$\begin{array}{l}\text { Standardized } \\
\text { Coefficients }\end{array}$} & t & Sig. \\
\cline { 3 - 5 } & B & Std. Error & Beta & & \\
\hline $\mathbf{1}$ & (Constant) & 2.668 & 0.745 & & 3.582 & 0.001 \\
& Sales force performance & 0.047 & 0.138 & 0.042 & .343 & 0.000 \\
\hline
\end{tabular}

a. Dependent Variable: organizational goal establishment

In the regression analysis presented above, the results go in support of the last hypothesis. The significance value of less than 0.05 identified that the salesforce performance in the pharmaceutical industry of Karachi contributes towards influencing organizational goal establishment. A positive value of risk factors coefficient (.042) also shows a positive relationship between the variables. From the analysis above, it can be noticed that coefficients are positively related to each other, with the significance value 0.000 that is less than 0.05 ; therefore rejecting the null hypothesis. It is identified that sales force performance contributes to organizational goal establishment.

\subsection{Summary}

The results and analysis indicated that there is a statistically significant impact of extrinsic and intrinsic variables on the motivation level of salesforce. In addition to this, it is also identified that increased level of motivation of sales force results in effective sales performance that leads towards effective process of organizational goals establishment.

\section{Conclusion, Recommendation and Future Suggestions}

This section of the study focuses on summarizing the entire research work and highlighting 
the main findings of the research. In addition to this, this section of the study also identified meaningful recommendations and suggestions for executing future research work. Limitations of the research study are also identified.

\subsection{Conclusion}

Taking into account the importance of motivation to achieve personal and organizational objectives, current research focuses on investigating the impact of employee motivation on the sales team on the overall performance of the organization. The purpose of this study was to define the interaction (Intrinsic, Extrinsic) between the motivational factors of the pharmaceutical sales team in terms of organizational performance. It assessed the relevance of modern motivation theory in an attempt to explain the importance of the determinants of motivation in the context of the sales team's performance in Karachi, Pakistan.

To implement current research and effectively solve research problems, researchers have chosen quantitative research design. The reason for choosing a quantitative study design is to investigate the effect of independent variables on dependent variables that are largely related to numerical statistics. Quantitative research designs will help researchers identify persuasive concepts from available data through statistical tests. In this study, the study focused on selecting people who are only active in the pharmaceutical industry in Karachi. Because the study was based on a quantitative study; therefore, the sample size chosen was based on only 200 participants in the pharmaceutical organization. In the current study, the study specifically contacted people in various research fields, from which the employees of the pharmaceutical companies were selected to obtain information on the motivations of the vendors. For this study, the data were analyzed using statistical tests and quantitative strategies. Raw data collected through a survey process using multiple regression analysis with SPSS.

Hypothesis 1: According to the results of the study, it is identified that salesforce working in the pharmaceutical industry of Karachi is highly influenced by extrinsic variables as compared to intrinsic variables. The results suggest that sales workers working in pharmaceutical companies prefer to have extrinsic aspects to improve their motivation level. Extrinsic factors taken into consideration in current research study includes acquiring fixed salary, allowances, medical expenses, insurance coverage and paid leaves. According to the statistical results, it is identified that there is statistically significant impact of extrinsic variables on the motivation level of the salesforce, as significant value was less than 0.05 , suggesting accepting the alternative hypothesis that is:

H1: Extrinsic variables have a significant positive effect on salesforce motivation.

Hypothesis 2: The results of the study indicated that intrinsic variables are not significantly associated with the sales force motivation. It is identified in the research study, as compared to extrinsic variables, intrinsic variables are not important for positively effecting the motivation level of pharmaceutical sales people working in Karachi. Respondents were asked to identify the significance of present working conditions, friendly relationship, encouragement, power in decision making and career progress for motivating the sales force. 
According to the results obtained, it is identified that these intrinsic variables are not associated with the motivation level of the employees working in pharmaceutical industry of Karachi. The statistical test suggests that there is no or less evidence to support the alternative hypothesis, hence rejecting the second hypothesis that proclaimed:

$\mathrm{H} 2$ : Intrinsic variables have a significant positive effect on salesforce motivation.

Hypothesis 3: This study proclaimed that motivation level of the sales forces positively affects the performance of sales team working in pharmaceutical industry of Karachi. According to the findings of the study, it is identified that with the high motivation levels, sales team demonstrates high performance in their job tasks. Respondents indicated that having a motivated work environment results in increasing their performance, hence achieving more targets, having secured job and positive association with the employers, colleagues and managers. The statistical test and results indicated that the data collection process gathered significant evidence that supports the hypothesis suggesting that:

H3: Salesforce motivation has significant positive effect on salesforce performance.

Hypothesis 4: The current research study suggested that different moderating variables also influence organizational performance. The results indicated that organizational goals, resources, opportunities for training and development, supporting work environment and technological resources available in organizational setting results in influencing the overall performance of organization. Respondents of the study indicated that presence of these variables results in improving performance of sales team and in results overall performance of the organization is improved. Statistical results indicated that having significant evidence results in supporting the hypothesis declaring that:

H4: Moderating variables also affect organizational performance.

Hypothesis 5: The current research study also explores the contribution of sales force performance towards the organizational goal establishment. The results indicated that the increased level of sales force performance contributes towards effective establishment and achievement of organizational goals. This research work contemplated that when pharmaceutical companies aim to operate in an effective and efficient manner, it is imperative to focus on improving performance of salesforce. This would result in establishing organizational goals and achieving those goals in a successful manner. Statistical results obtained enough evidence to reject the null hypothesis and supporting hypothesis that proclaimed that:

H5: Salesforce performance contributes to organizational goal establishment.

\subsection{Recommendations and Future Research}

From the completion of this work generate some recommendations for future research projects carried out in the administrative area and then be able to expand to other operational and technical areas of the company.

In this regard, it is recommended that the factors be previously delimited motivators that will take into account for the analysis and that from these base elements can be considered more 
elements that can determine the employee performance, to avoid too much breadth in the subject and lack of precision in the results; in the same way the scope must be taken into account and budget to be able to apply certain motivational strategies.

It is also recommended that the focus on satisfaction and personal growth of employees, regardless of the position they occupy, ensure that the values and organizational objectives are always present, which will allow them to obtain higher performance by its employees generating greater organizational performance.

It is recommended that pharmaceutical companies always have a vision for the future and by implementing the proposal, develop a strategy of corporate-level motivation, which excites employees for the future of the organization and encourages them to feel identified with it and thus achieve both personal and organizational satisfaction.

\subsection{Acknowledgements}

I would like to pay my gratitude to Allah Al-Mighty who has given me strength, courage and knowledge to conduct this research and complete it. I want to pay special thanks to my instructor, Dr Shameel Ahmed Zuberi, who has been a source of knowledge, guidance and support throughout the research procedure. Finally, I would like to thank my family and friends, who supported me in this research work. Without their assistance, it was not possible for me to complete this project. Jazak ALLAH.

\section{References}

Ahmad, I., Danish, R. Q., Ali, S. A., Ali, H. F., \& Humayon, A. A. (2019). A Comparative Study of Banking Industry Based on Appraisal System, Rewards and Employee Performance. SEISENSE Journal of Management, 2(1), 1-11. https://doi.org/10.33215/sjom.v2i1.64

Ansoglenang, G., Thompson, J. D., \& Awugah, S. A. (2019). Mapping out the Theories of Motivation: Lessons for Administrators in Public Institutions. Arts Social Sci J, 10(444), 2.

Belrhiti, Z., Van Damme, W., Belalia, A., \& Marchal, B. (2019). Does public service motivation matter in Moroccan public hospitals? A multiple embedded case study. International journal for equity in health, $18(1), \quad$ https://doi.org/10.1186/s12939-019-1053-8

Black, S., Gardner, D. G., Pierce, J. L., \& Steers, R. (2019). Process Theories of Motivation. Organizational Behavior.

Boachie-Mensah, F. O., \& Adu-Poku, F. (n. d.). Investigating Factors Contributing to Sales Force Motivation in the Insurance Companies in the Central Region of Ghana.

Chowdhury, M. S. (2007). Enhancing motivation and work performance of the salespeople: the impact of supervisors' behavior. African Journal of Business Management, 1(9).

Galli, B. J. (2020). Impact and Role of Motivation Theories in Continuous Improvement Environments: A Reflection of Literature. International Journal of Service Science, Management, Engineering, and Technology (IJSSMET), 11(1), 1-13. https://doi.org/10.4018/IJSSMET.2020010101 
González-Cruz, T. F., Botella-Carrubi, D., \& Martínez-Fuentes, C. M. (2019). Supervisor leadership style, employee regulatory focus, and leadership performance: A perspectivism approach. Journal of Business Research, 101, 660-667. https://doi.org/10.1016/j.jbusres.2019.01.065

Gross, H. P., Thaler, J., \& Winter, V. (2019). Integrating public service motivation in the job-demands-resources model: An empirical analysis to explain employees' performance, absenteeism, and presenteeism. International Public Management Journal, 22(1), 176-206. https://doi.org/10.1080/10967494.2018.1541829

Hameed, W., Dahri, A., Hayat, R., Hashmi, F., Haneef, A., \& Qureshi, M. (2018). Factors influencing Sales Force Motivation and Marketing Performance A case of Malaysian Pharmaceuticaland Biotechnological Companies. International Journal of Advanced Biotechnology and Research, 9(1), 1136-1147.

John, A. G., Francis, A. I., \& Innocent, I. (2012). Improving sales performance through sales force motivation strategies: A study of pharmaceutical firms in Nigeria. Int. J. Buss. Mgt. Eco. Res, 3(5), 620-626.

John, G., \& Weitz, B. (1989).Salesforce compensation: An empirical investigation of factors related to use of salary versus incentive compensation. Journal of Marketing Research, 26(1), 1-14. https://doi.org/10.1177\%2F002224378902600101

Klein, M. (2019). Self-Determination Theory: Basic Psychological Needs in Motivation, Development, and Wellness. SociologickyCasopis, 55(3), 412-413.

Koh, A. C., Gammoh, B. S., \& Okoroafo, S. C. (2011). The antecedents of sales force motivation: An empirical investigation in the insurance industry in Singapore. International Journal of Marketing Studies, 3(3), 3. https://doi.org/10.5539/ijms.v3n3p3

Lee, M., \& Bong, M. (2019). Relevance of goal theories to language learning research. System, 86, 102-122. https://doi.org/10.1016/j.system.2019.102122

Malik, M. E., \& Naeem, B. (2009). Motivational preferences of pharmaceutical salesforce: Empirical evidence from Pakistan. Pakistan Economic and Social Review, 19-30. https://doi.org/10.1016/j.system.2019.102122

Malik, M. E., Naeem, B., \& Ahmad, W. (2012). Creative Performance of Pharmaceutical Sales Force: Role of Intrinsic Motivation and Learning Goal Orientation. Journal of Basic and Applied Scientific Research, 2(12), 12633-12640.

McCarthy, D., Wei, P., Homberg, F., \& Tabvuma, V. (2019, February). Public service motivation in the Chinese public and private sectors. In Evidence-based HRM: a Global Forum for Empirical Scholarship. Emerald Publishing Limited. https://doi.org/10.1108/EBHRM-06-2018-0039

Miao, Q., Eva, N., Newman, A., \& Schwarz, G. (2019). Public service motivation and performance: The role of organizational identification. Public Money \& Management, 39(2), 77-85. https://doi.org/10.1080/09540962.2018.1556004 
Mishra, U. S., Sahoo, S. K., \& Sahoo, S. (2012). Impact of Sales Force Satisfaction on Motivation: An Empirical Study in Pharmaceutical Industry. European Journal of Social Sciences, 34(1), 70-77.

Mugasa, B. B. (2013). The Role of Motivation and Its Effects on Sales Force Performance: A Case Study of Mwananchi Communication Company Limited, Dar-es-Salaam (Doctoral dissertation, The Open University of Tanzania). http://repository.out.ac.tz/id/eprint/1055

Naqvi, A. (2019). Impact of Sales Force Automation System on Performance of Salesman: Pakistani Companies' Perspective. Sir Syed University Research Journal of Engineering \& Technology, 9(1). https://doi.org/10.33317/ssurj.v1i1.111

Obikeze, C. O. (2016). Effects of Motivation on Salesforce Performance in Guinness Nigeria Plc and Mobile Telecommunication Network in South-East, Nigeria (Doctoral dissertation).

Parvin, M. M., \& Kabir, M. N. (2011). Factors affecting employee job satisfaction of pharmaceutical sector. Australian Journal of Business and Management Research, 1(9), 113.

Reddy, M. V. B., Rao, P. B., \& Venugopal, I. (n. d.). The Importance of Compensation management for improving the Performance of Sales force.

Ritz, A., Brewer, G. A., \& Neumann, O. (2016). Public service motivation: A systematic literature review and outlook. Public Administration Review, 76(3), 414-426. https://doi.org/10.1111/puar.12505

Roopai, D. (2012). Job Satisfaction Among Pharmaceutical Sales Represantatives in the Context of Herzberg's Motivation-hygiene Theory (Doctoral dissertation, University of KwaZulu-Natal, Durban).

Sahoo, S. K., Routray, P., \& Dash, A. K. (2014). Does motivation really count for sales force performance in pharmaceutical industry. Business and Management Research, 3(2), 1-9. https://doi.org/10.5430/bmr.v3n2p1

Sahoo, S. K., Routray, P., \& Jena, P. C. (2012). Impact of satisfaction on sales force performance: An empirical study in Indian pharmaceutical industry. British Journal of Humanities and Social Sciences, 7(2), 86-102.

Sari, N. P. R., Bendesa, K. G., \& Antara, M. (2019). The influence of quality of work life on employees' performance with job satisfaction and work motivation as intervening variables in star-rated hotels in Ubud tourism area of Bali. Journal of Tourism and Hospitality Management, 7(1), 74-83. https://doi.org/10.15640/jthm.v7n1a8

Schwarz, G., Newman, A., Cooper, B., \& Eva, N. (2016). Servant leadership and follower job performance: The mediating effect of public service motivation. Public Administration, 94(4), 1025-1041. https://doi.org/10.1111/padm.12266

Shin, J., \& Grant, A. M. (2019). Bored by Interest: How Intrinsic Motivation in One Task Can Reduce Performance on Other Tasks. Academy of Management Journal, 62(2), 415-436. https://doi.org/10.5465/amj.2017.0735 


\section{Macrothink}

Umar, G. (2010). The influence of compensation on performance of sales representatives of pharmaceutical companies based in ilorin-nigeria. African Research Review, 4(3). https://doi.org/10.4314/afrrev.v4i3.60258

Van den Broeck, A., Carpini, J., \& Diefendorff, J. (2019). Work motivation: Where do the different perspectives Lead us. The Oxford handbook of human motivation. Oxford University Press. https://doi. org/10.1093/oxfordhb/9780190666453.013,27

van der Kolk, B., van Veen-Dirks, P. M., \& terBogt, H. J. (2019). The impact of management control on employee motivation and performance in the public Sector. European Accounting Review, 28(5), 901-928. https://doi.org/10.1080/09638180.2018.1553728

Wiese, M., \& Coetzee, R. (2013). The importance of non-financial motivators to pharmaceutical sales representatives: A demographic study. Southern African Business Review, 17(1), 23-56.

Wright, B. E., Hassan, S., \& Christensen, R. K. (2017). Job choice and performance: Revisiting core assumptions about public service motivation. International Public Management Journal, 20(1), 108-131. https://doi.org/10.1080/10967494.2015.1088493

Yaqoob, M., Mushtaq, R., Akhter, M., Naaz, M., \&Yaqoob, A. (n. d.). Impact of Motivation on Sales Force Performance and Turnover Intention Pharmaceuticals Industry.

\section{Copyright Disclaimer}

Copyright for this article is retained by the author(s), with first publication rights granted to the journal.

This is an open-access article distributed under the terms and conditions of the Creative Commons Attribution license (http://creativecommons.org/licenses/by/3.0/). 